\title{
BMJ Open Relevance of healthcare reimbursement data to monitor syphilis epidemic: an alternative surveillance through the national health insurance database in France, 2011-2013
}

\author{
Ndeindo Ndeikoundam Ngangro, ${ }^{1}$ Delphine Viriot, ${ }^{1}$ Etienne Lucas, ${ }^{1}$ \\ Marjorie Boussac-Zarebska, ${ }^{1}$ Florence Lot, ${ }^{1}$ Nicolas Dupin, ${ }^{2,3}$ Guy La Ruche ${ }^{4}$
}

To cite: Ndeikoundam Ngangro N, Viriot D, Lucas E, et al. Relevance of healthcare reimbursement data to monitor syphilis epidemic: an alternative surveillance through the national health insurance database in France, 2011-2013. BMJ Open 2018;8:e020336. doi:10.1136/ bmjopen-2017-020336

\section{- Prepublication history for} this paper is available online. To view these files, please visit the journal online (http://dx.doi. org/10.1136/bmjopen-2017020336).

Received 6 November 2017 Revised 20 April 2018 Accepted 7 June 2018

Check for updates

(C) Author(s) (or their employer(s)) 2018. Re-use permitted under CC BY-NC. No commercial re-use. See rights and permissions. Published by BMJ.

For numbered affiliations see end of article.

Correspondence to Dr Ndeindo Ndeikoundam Ngangro;

ndeindo.ndeikoundam@ santepubliquefrance.fr

\section{ABSTRACT}

Objective In France, surveillance of early syphilis (primary, secondary and early latent) relies on the clinician-based ResIST sentinel network. Although ResIST enables the monitoring of trends, a complete picture of the syphilis epidemic is not possible. More specifically, cases reported by this network are mostly diagnosed in free sexually transmitted infection clinics and hospitals $(75 \%$ and $24 \%$, respectively). This study aims to estimate the number and rate of diagnoses made outside these health facilities by exploring health insurance data.

Methods An algorithm combining healthcare reimbursements for specific diagnostic tests and recommended treatment was fitted to identify syphilis cases. Sensitivity analyses were used to validate the algorithm. Age-standardised and gender-standardised diagnosis rates were estimated using census data. Results Between 2011 and 2013, 12644 (7.5 cases per 100000 inhabitants) reimbursements were made for syphilis-related diagnoses. The annual number of cases increased by $22 \%$ from 2011 ( $\mathrm{n}=3771$, rate $=6.7 / 100$ 000) to $2013(\mathrm{n}=4589$, rate $=8.2 / 100000)$. The rate of syphilis diagnosis increased in men from $12.9 / 100$ 000 to $16.0 / 100000$, while it remained steady in women at approximately $1.8 / 100000$. The disease burden was greatest in French overseas territories (18.1/100000) and in the Paris area (11.7 cases/100000).

Conclusion Despite the lack of data on the number of confirmed diagnoses and information on sexual behaviour, these findings demonstrate the relevance of analysing insurance data to help monitor the syphilis epidemic in patients who visit general practitioners and non-hospitalbased specialists. Thus, reimbursement database might be a relevant alternative source of continuous information on syphilis in countries with similar insurance-based healthcare systems.

\section{INTRODUCTION}

Syphilis continues to be a major public health concern in France since its upsurge in $2000 .{ }^{1}$ The epidemic is predominantly spreading in men who have sex with men (MSM),

\section{Strengths and limitations of this study}

- The study has a large coverage of the national health insurance in France (almost the whole population).

- The study used comprehensive reimbursement data.

- The study used an algorithm combining individual linkage of a specific treatment (benzathine penicillin $\mathrm{G}$ ) and recommended combinations of treponemal test and non-treponemal test to identify cases as diagnostic results are not available.

- Clinical details and sexual behaviour information are not collected in the reimbursement database.

who represent more than $80 \%$ of reported cases each year. Between 2013 and 2015, an increase of $56 \%$ was seen in this population. Despite much smaller numbers, a rise has also been observed in heterosexuals since 2012. ${ }^{2}$

Considering this uncontrolled situation, the fact that syphilis is a risk factor for HIV transmission and its non-negligible associated complications (neurosyphilis and others), accurate epidemiological surveillance can help guide and evaluate prevention interventions in the context of pre-exposure prophylaxis for HIV infection. ${ }^{3-5}$

In France, national surveillance of early syphilis (primary, secondary and early latent $(<1$ year $))$ relies on the voluntary clinician-based network ResIST. It gathers demographic, clinical, biological and behavioural data. ${ }^{6}$ Although surveillance data enable the monitoring of epidemiological trends and characteristics through consistently participating diagnosis centres, they do not provide an accurate picture of the epidemic because of a lack of representativeness. Indeed, reported cases are mostly diagnosed in free sexually transmitted infection (STI) clinics (75\% in 2014) and hospital consultations 
$(24 \% \text { in } 2014)^{2}$ given the small number of general practitioners (GPs) and non-hospital-based specialists in the network.

In France, free STI clinics are primarily targeting highrisk groups and socially disadvantaged ones, but anybody can visit these public facilities. Nevertheless, these STI clinics are commonly visited by informed population, whereas most individuals are likely to seek care by visiting GPs, private clinics or public hospitals, thanks to the national health insurance covering almost the whole population.

To complete the picture of the epidemic in France, this study aimed to estimate the contribution (number, rate and trends) of diagnoses made outside of free STI clinics and hospitals by exploring health insurance data.

\section{METHODS}

\section{Study population}

The study population included all persons covered by the national health insurance system in France (approximately 63 million beneficiaries or approximately $95 \%$ of the population).$^{78}$

\section{Health insurance data}

The French health insurance databases are stored anonymously in a huge data warehouse, the French national health insurance database ('Système national d'information inter-régime de l'assurance maladie' (SNIIR-AM)).
The SNIIR-AM contains data on healthcare reimbursements and sociodemographic information relative to each beneficiary. These data are linkable through a unique identifier encrypted and replaced by a non-reversible key in various databases. ${ }^{79}$ The interscheme consumption data ('données de consommation inter-régimes' (DCIR)), including non-hospital-based healthcare reimbursements, were specifically used in this study.

The DCIR collects a large amount of information including demographic data (age, gender, place of residency, affiliate insurance scheme and others) and non-hospital-based healthcare data (type of prescriber and dispenser, diagnostic test codes, drug codes, exact pharmaceutical form, number of dispensed units for each affiliated person), prospectively and daily. ${ }^{7}$ Free STI healthcare information, which is not collected in the DCIR, and hospital-based diagnoses data were not analysed in this study. ${ }^{78}$

\section{Case definitions}

As clinical details (ie, symptoms, diagnostic results) are not collected in the DCIR, an algorithm combining reimbursements for diagnostic tests and treatments was fitted to identify syphilis cases (figure 1).

Assuming that syphilis treatment is mainly prescribed over a 30-day period after diagnosis and that a duration of at least 365 days is observed between two episodes of syphilis in the same patient due to temporary immunity,
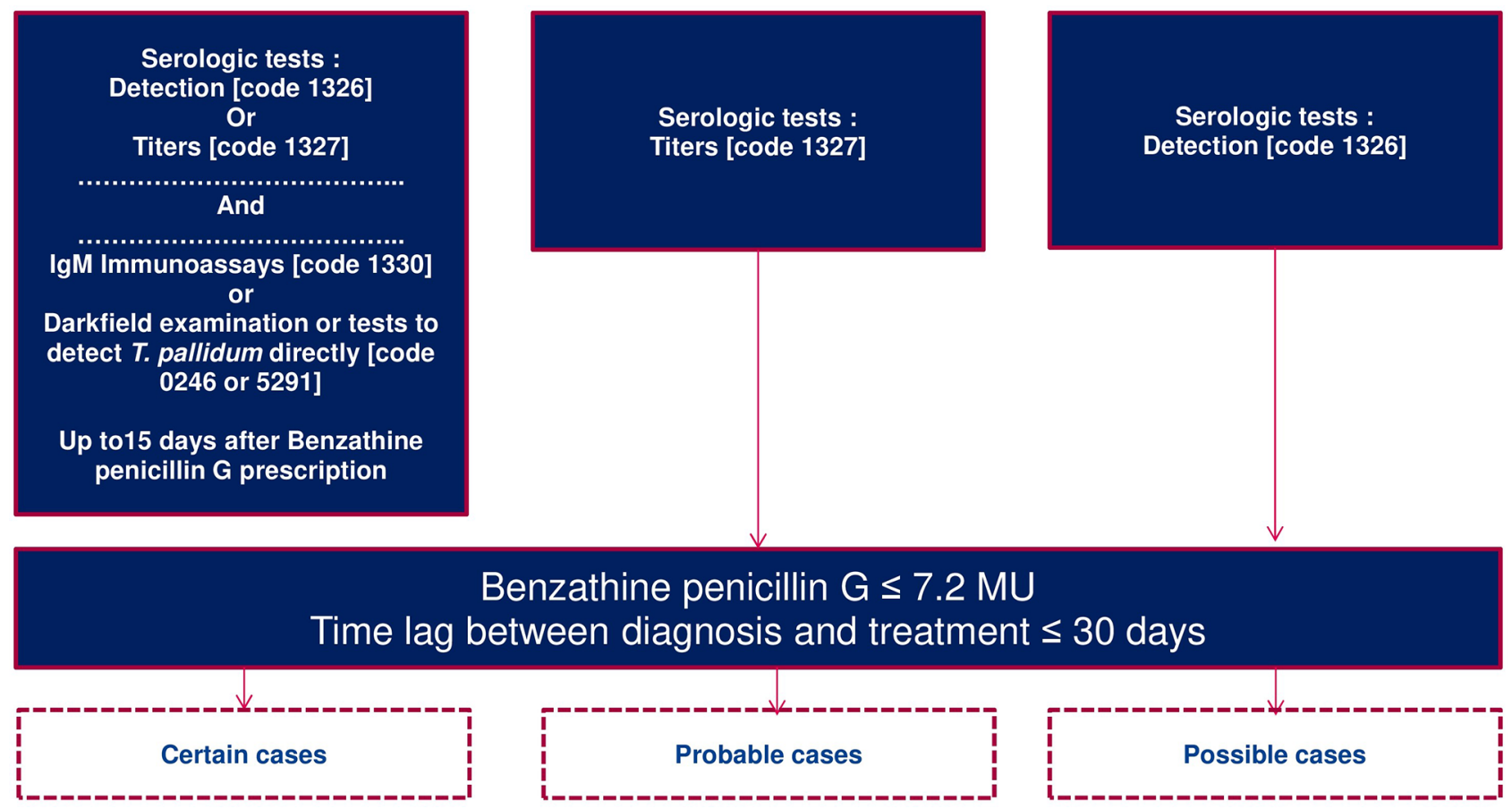

Benzathine penicillin $\mathrm{G} \leq 7.2 \mathrm{MU}$

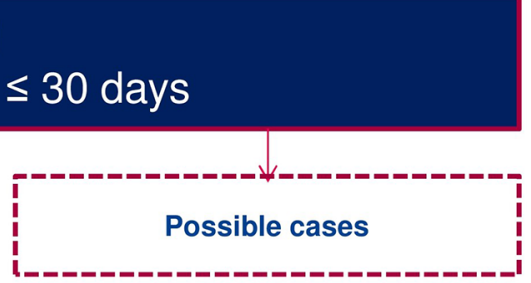

Figure 1 Syphilis algorithm, SNIIR-AM DCIR database, France, 2011-2013. Pharmaceutical codes: code 3039095, benzathine penicillin G 2.4 MU; code 3039089, benzathine penicillin G 1.2 MU; code 3039103, benzathine penicillin G 0.6 MU. Diagnostic test codes: code 1326 (group 1: venereal disease research laboratory or rapid plasma reagin; and group 2: Treponema pallidum hemagglutination assay or Treponema pallidum particle agglutination or Treponema pallidum latex agglutination or enzyme immunoassay or fluorescent treponemal antibody absorption test); code 1327 (same group 1 and 2 serological tests (reimbursement is only possible in the event of a positive detection result)). DCIR, données de consommation inter-régimes; MU, million units; SNIIR-AM, Système national d'information inter-régime de l'assurance maladie. 
we selected and combined reimbursement codes corresponding to the prescriptions according to syphilis screening and treatment guidelines. ${ }^{10-12}$ Combinations of treponemal tests (TT: serological tests (detection, titres), IgM immunoassays, tests to detect Treponema pallidum directly (darkfield examination or other test)) and non-treponemal tests (NTT: serological tests (detection, titres) ) preceding a prescription of benzathine penicillin G (BPG) up to 7.2 million units (MU) over 30 days defined three types of incident syphilis cases. The threshold of 7.2 MU (regimens for late syphilis) was chosen to identify any incident syphilis irrespective of its stage. ${ }^{10-14}$

Finally, three types of incident cases were defined according to the combinations of diagnostic tests (figure 1):

- Cases considered as certain (hereafter 'certain cases') included recently infected individuals with a combination of TT and NTT (serological tests detection code 1326 (group 1: venereal disease research laboratory or rapid plasma reagin; and group 2: Treponema pallidum hemagglutination assay or Treponema pallidum particle agglutination or Treponema pallidum latex agglutination or enzyme immunoassay or fluorescent treponemal antibody absorption test); or titres code 1327 (same group 1 and 2 serological tests in the event of a positive detection result) and one test among IgM immunoassays (code 1330), darkfield examination or tests to detect $T$. pallidum directly (code 0246 or 5291)).

- 'probable cases' included individuals with TT/NTT and titres of NTT corresponding to active syphilis (serological tests titres (code 1327)).

- 'possible cases' included individuals with a combination of TT and NTT without titre test reimbursement (serological tests (code 1326)).

This algorithm was validated after analysing the consistency of syphilitic tests and BPG prescription according to available data (estimated proportion of pregnant women tested for syphilis in 2011 and the annual number of births in France, number of BGP unit sales, male to female ratio of syphilis, and regions with the highest incidence of HIV, chlamydial and gonococcal infections (ie, overseas regions, Paris area)). ${ }^{15-17}$ The study period was restricted to 3 years, from January 2011 to December 2013, before the stock depletion of BPG in France between 2014 and 2016. Sensitivity analyses completed the validation process, considering the distribution of BPG doses and the time between treatment and diagnosis reimbursement.

\section{Statistical analysis}

The annual number of identified syphilis cases was estimated. Cases were described according to age, gender and region of residence. Finally, age-standardised and gender-standardised diagnosis rates were calculated for individuals aged 15 years and over using census data. SAS Enterprise Guide V.4.3 was used for statistical analyses.

\section{Ethics statement}

Ethical approval was granted by the French Data Protection Agency (CNIL) with decrees dated 20 June 2005 and 1 December 2011. These decrees strictly restrict access to anonymised SNIIR-AM data to accredited analysts. ${ }^{18}$ Therefore, no individual consent was required for this study.

\section{Patient and public involvement}

Patients and the public were not involved in the design and the conduct of the study.

\section{RESULTS}

A total of 4.3 million individuals were reimbursed for syphilis tests (22.1/1000 inhabitants) during the study period. Approximately 1.4 million individuals were tested for syphilis yearly, from $2011 \quad(\mathrm{n}=1376$ 180, 21.2/1000 inhabitants) to 2013 ( $\mathrm{n}=1521$ 774, 23.2/1000 inhabitants). Three-quarters of individuals screened for syphilis were women, mainly between 15 and 59 years old (96\%). Approximately 40000 individuals were reimbursed for BPG prescription $(20.5 / 100000$ inhabitants) between $2011(\mathrm{n}=12$ 810, 19.7/100 000) and $2013(\mathrm{n}=13$ 944, 21.3/100 000). Of these individuals, two-thirds were male.

Between 2011 and 2013, 12644 syphilis diagnoses were identified: 3437 certain cases (27\%), 4581 probable cases $(36 \%)$ and 3626 possible cases $(37 \%)$ (figure 2$)$. The annual number of syphilis diagnoses increased by $22 \%$ from $2011(\mathrm{n}=3771)$ to $2013(\mathrm{n}=4589)$ (figure 3). Most were men (87\% in 2011 and $89 \%$ in 2013). The men to women ratio was steady over time and was higher for probable cases $(8: 1)$ than for certain and possible cases (7:1 and 6:1, respectively). Most of the cases $(75 \%)$ were treated with less than 7.2 MU of BPG.

During the study period, the overall rate of diagnosis was estimated at 7.5 cases $/ 100000$ inhabitants aged 15 years and over (figure 4). It rose from 6.7/100 000 in 2011 to 8.2/100000 in 2013. Between 2011 and 2013, a higher rate than the national level was estimated in 9 of 24 regions, with the highest burden observed in French overseas territories (18.1 diagnoses/100000) and in the Paris area (11.7 diagnoses/100 000 inhabitants). Of these nine regions, the rates increased between 2011 and 2013 in Alsace, Provence-Alpes-Côte d'Azur and the Paris area, whereas it remained relatively stable in the other regions.

The rate of syphilis diagnosis increased in men from $12.9 / 100000$ in 2011 to $16.0 / 100000$ in 2013 , while it remained stable at approximately 1.8/100000 in women. During the study period, the highest rate of diagnoses (up to 26.2/100000) was observed in men aged 40-44 years old (figure 5). The age structure shows that $92 \%$ of cases were between 15 and 59 years old in both sexes.

\section{DISCUSSION}

Although the primary limitation of using reimbursement data is the lack of biological results, clinical details 


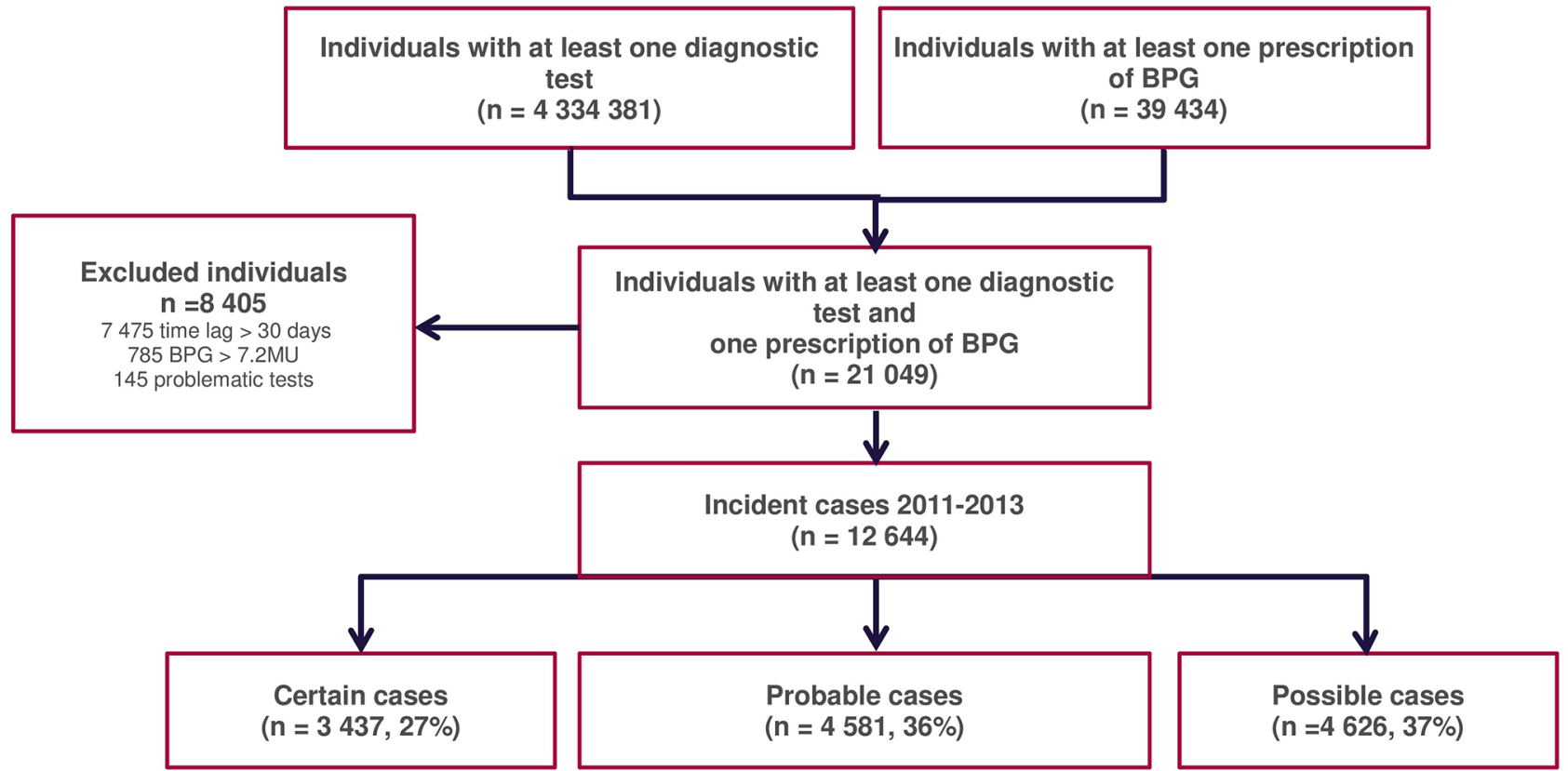

Figure 2 Syphilis case identification in reimbursement claims databases, SNIIR-AM DCIR database, France, 20112013. BPG, benzathine penicillin G; DCIR, données de consommation inter-régimes; MU, million units; SNIIR-AM, Système national d'information inter-régime de l'assurance maladie.

and sexual behaviour information, this type of proxy approach has already been validated using other algorithms in several contexts. ${ }^{79-21}$ Several training sessions were prerequisites by the national health insurance before getting the authorisation to use the SNIIR-AM and to build the syphilis algorithm in this study. ${ }^{78}$ But any changes in the availability of diagnostic tests or BPG may impact the usage of this algorithm. Accordingly, updates could be necessary in such a situation (eg, a temporary shortage of BPG requires adding replacement drugs in the algorithm). Nevertheless, the large coverage of health insurance in France (almost the whole population), ${ }^{78}$

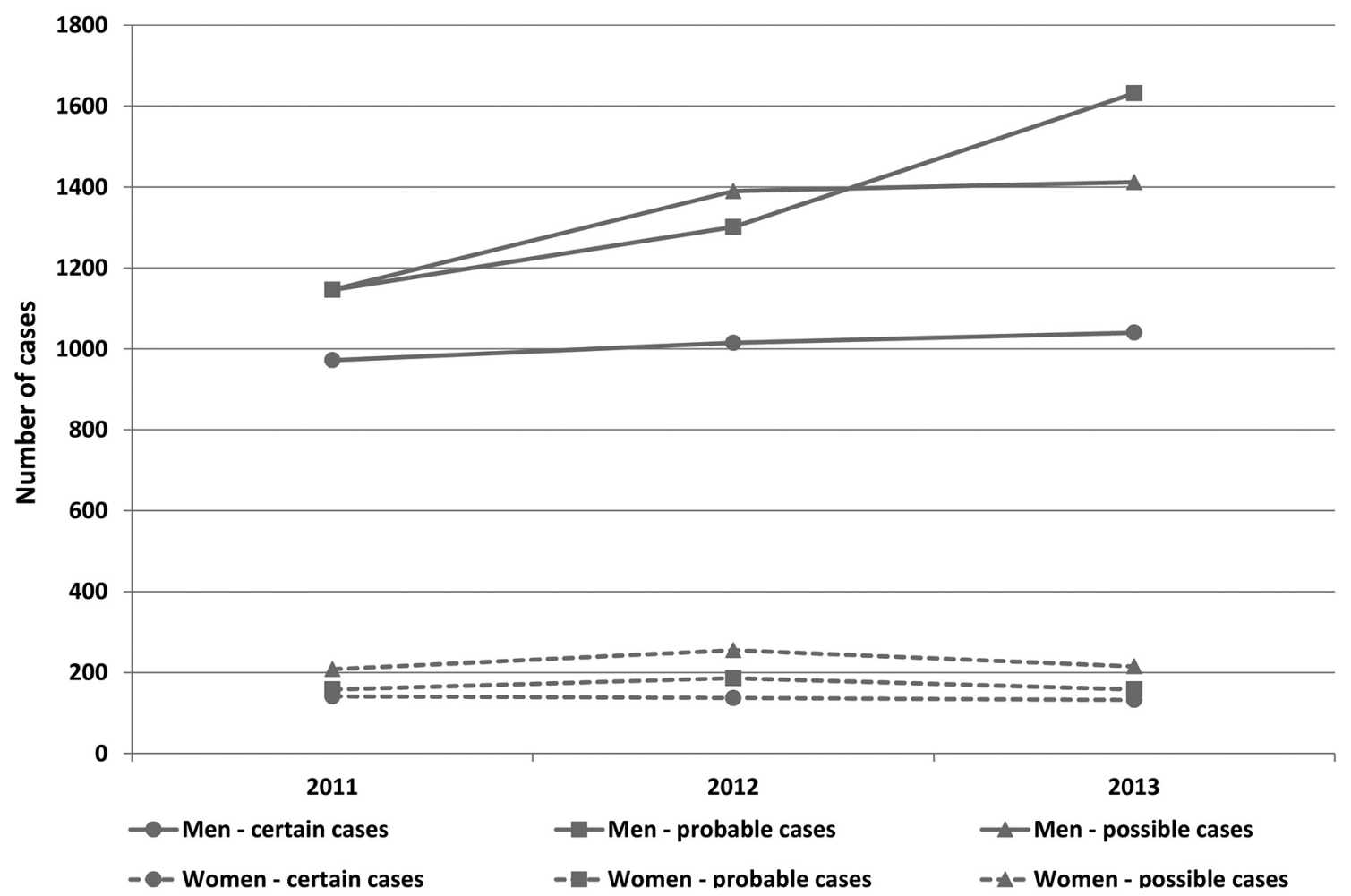

Figure 3 Trends of syphilis diagnoses reimbursed by the French health insurance system, SNIIR-AM DCIR database, France, 2011-2013. DCIR, données de consommation inter-régimes; SNIIR-AM, Système national d'information inter-régime de l'assurance maladie. 


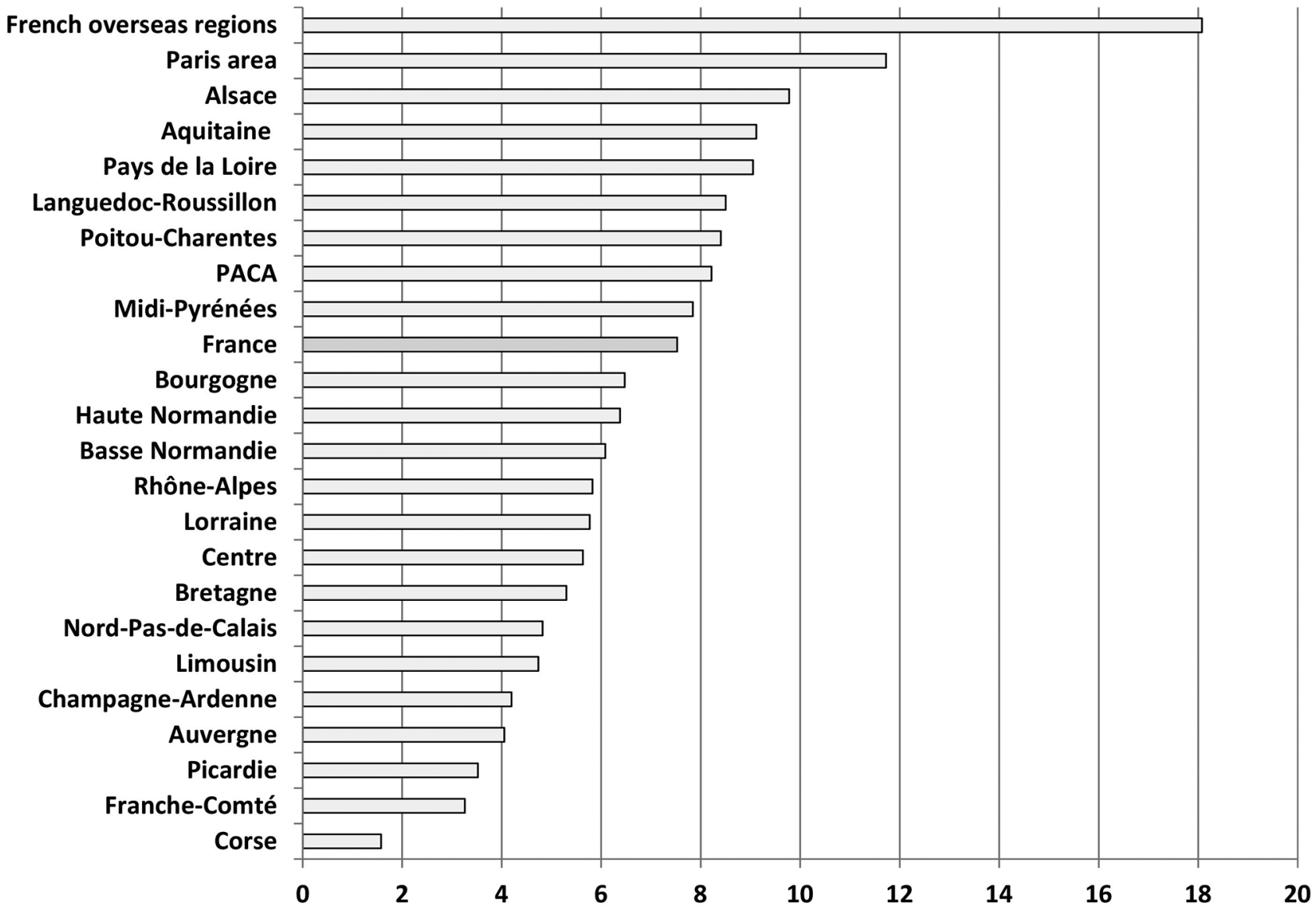

Figure 4 Number of syphilis diagnoses per 100000 inhabitants by region, syphilis SNIIR-AM DCIR, 2011-2013. The French overseas regions: Guadeloupe, Martinique, French Guyana and French Reunion Island. DCIR, données de consommation interrégimes; PACA, Provence-Alpes-Côte d'Azur; SNIIR-AM, Système national d'information inter-régime de l'assurance maladie.

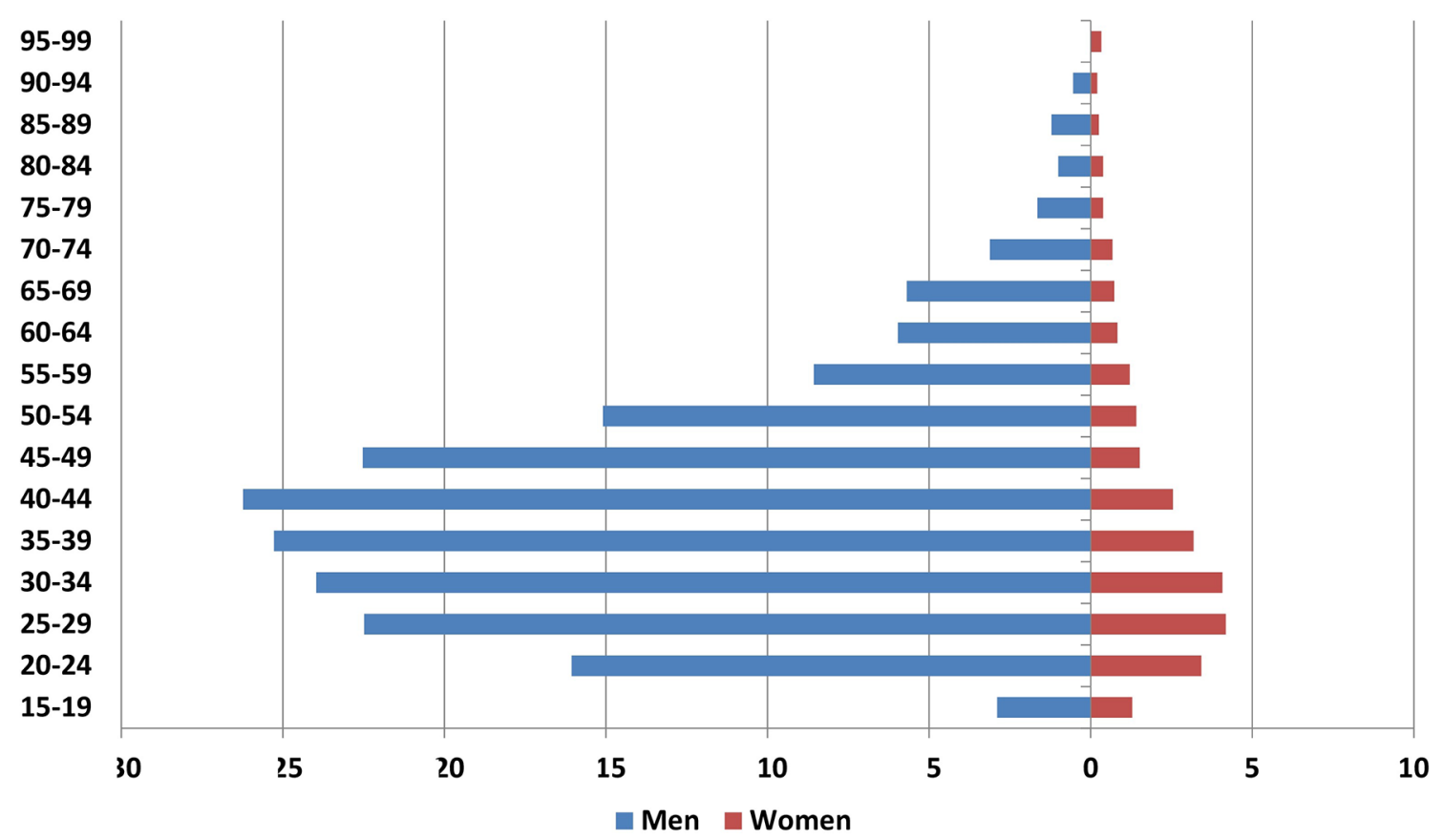

Figure 5 Rates of syphilis diagnoses by age and gender, SNIIR-AM DCIR, France, 2011-2013. Rate=number of diagnoses/100000 inhabitants. DCIR, données de consommation inter-régimes; SNIIR-AM, Système national d'information inter-régime de l'assurance maladie. 
the comprehensiveness of reimbursement data and individual linkage of a specific treatment (BPG), and recommended combinations of TT and NTT demonstrate the relevance of using SNIIR-AM databases to monitor syphilis diagnoses in France.

Healthcare reimbursement data for the whole population covered by the national health insurance can therefore be used to estimate the number of individuals tested for syphilis, the number of cases and positivity rates according to age, sex and region. These epidemiological indicators are easily understandable. They enable trends to be precisely monitored over time, especially at a local level, while trends based on sentinel networks data in France are currently difficult to interpret precisely without information about the participation level and the networks' sensitivity.

The sharp increase in the rate of diagnoses (from 6.7/100 000 to $8.8 / 100000$ between 2011 and 2013) reflects the rising trends in syphilis epidemic observed in Western European countries comparable with France. ${ }^{3}$ This increase might result from a growing tendency towards more risky sexual behaviour. However, these numbers of diagnoses and rates almost certainly underestimate the disease burden as they exclude undiagnosed cases, hospital-based diagnoses and diagnoses provided in free STI clinics.

Our results-notably the number of annual cases (4589 in 2013) compared with the incidence in other European countries (4656 cases in the UK, 3568 cases in Spain and 5718 cases in Germany in $2014^{3}$ )—demonstrate that GPs and non-hospital-based specialists still play a role in STI management in France. Consequently, health insurance data should be used to complement incidence estimates. A study using the UK Clinical Practice Research Datalink anonymous primary care records service found similar findings for chlamydial infections and gonorrhoea in England. ${ }^{22}$

In our study, the annual gender distribution of syphilis cases was coherent with surveillance data in Western European countries including France. ${ }^{3}$ The high proportion of men (over 80\%) corresponds to situations reported in Germany, Ireland, the Netherlands, Norway and the UK. ${ }^{3}$ Nevertheless, the proportion of women $(11 \%$ in the national health insurance data in 2013) compared with $4 \%$ reported by the ResIST sentinel network might reflect differences between the populations using free STI services and those diagnosed by non-hospital-based physicians. ${ }^{6}$ Performing a behavioural survey in the population diagnosed with syphilis and other STIs by GP and non-hospital-based physicians could be useful in knowing the characteristics of cases by transmission mode (MSM, heterosexual).

The predominance of women (at least $75 \%$ ) among tested individuals each year in our study is coherent with findings from the antenatal syphilis detection programme in France (90\% of pregnant women were tested for syphilis in 2011; less than 800000 annual live births in France), and the gender-based distribution of syphilis cases, with an overall male to female ratio close to 7 , reflects the national surveillance results (more than $80 \%$ men among syphilis cases reported in the ResIST network), demonstrating the relevance of using the algorithm. ${ }^{215-17}$ Moreover, the proportion of TT and NTT titre tests (99\%) among the reimbursed diagnostic tests is also consistent with physicians' prescriptions in the surveillance data.

The distribution of cases by BPG dose shows that $75 \%$ of identified cases might be early syphilis cases $(<1$ year $)$ considering that BPG prescription was under 7.2 MU. Consequently, a quarter of syphilis diagnoses made outside of hospitals and free STI clinics in France may correspond to late syphilis cases, which are not currently monitored. These proportions are close to those found in US surveillance data. ${ }^{23}$ Therefore, the surveillance of transmission dynamics (early syphilis) and delayed syphilis diagnosis (late syphilis) might be possible using insurance data.

The comprehensiveness of reimbursement data and their coverage enable spatial and temporal calculations at the regional level. ${ }^{24}{ }^{25}$ Accordingly, subnational surveillance is possible and standardised rates can be used to compare different areas. In this study the highest rates of syphilis were observed for French overseas territories, whereas the ResIST sentinel network currently underestimates the burden of the epidemic in those areas. ${ }^{6}$ These rates are consistent with the findings of a laboratory survey conducted in 2012, which estimated the highest rates of gonorrhoea and chlamydial infections in the same areas. ${ }^{26}$ Despite differences in data collection techniques, reimbursement data confirm the results of network surveillance data by demonstrating that a quarter of annual cases of syphilis are reported in the Paris area. ${ }^{6}$

\section{CONCLUSION}

In France, a complete picture of the syphilis epidemic might result from summing up the number of reimbursed diagnoses with diagnoses made in hospitals and free STI clinics. The annual incidence rate estimates could therefore help to accurately monitor the epidemic's evolution and guide prevention policies. Using reimbursement data could also help to monitor syphilis testing at the subnational level, to analyse local responses to the epidemic and to investigate outbreaks. Thus, healthcare reimbursement database might be a relevant alternative source of continuous information on syphilis in countries with similar insurance-based healthcare systems.

\section{Author affiliations}

${ }^{1}$ Sante publique France, The National Public Health Agency, Saint Maurice, France ${ }^{2}$ National Reference Center for STI-Syphilis, APHP, Hôpital Cochin, Paris, Paris, France

${ }^{3}$ Université Paris Descartes, Sorbonne Paris Santé, Paris, France

${ }^{4}$ Unité veille et sécurité sanitaire/Prévention et promotion de la santé, Délégation départementale de l'Hérault, Regional Health Agency of Occitanie, Montpellier, France 
Acknowledgements We acknowledge the French national health insurance system for allowing access to the healthcare reimbursement data. We are also particularly grateful to Jude Sweeney for copyediting the final version of this article.

Contributors DV, EL, FL, GLR, MB-Z, ND and NNN contributed to the conception and the design of the study. EL, GLR, MB-Z and ND built the algorithm. DV and EL performed the statistical analyses. DV, EL, FL, GLR, MB-Z, ND and NNN contributed to the interpretation of the data. NNN drafted the manuscript. All authors contributed to, reviewed and approved the final manuscript.

Funding The authors have not declared a specific grant for this research from any funding agency in the public, commercial or not-for-profit sectors.

Competing interests None declared.

Patient consent Not required.

Ethics approval Ethical approval was granted by the French Data Protection Agency (CNIL) with decrees dated 20 June 2005 and 1 December 2011. These decrees strictly restrict access to anonymised SNIIR-AM data to accredited analysts. Therefore, no individual consent was required for this study.

Provenance and peer review Not commissioned; externally peer reviewed.

Data sharing statement Ethical approval granted by the French Data Protection Agency (CNIL) is needed to access the data, and the national health insurance strictly restricts access to anonymised SNIIR-AM data to accredited analysts.

Open access This is an open access article distributed in accordance with the Creative Commons Attribution Non Commercial (CC BY-NC 4.0) license, which permits others to distribute, remix, adapt, build upon this work non-commercially, and license their derivative works on different terms, provided the original work is properly cited, appropriate credit is given, any changes made indicated, and the use is non-commercial. See: http://creativecommons.org/licenses/by-nc/4.0/.

\section{REFERENCES}

1. Couturier $E$, Michel A, Janier M, et al. Syphilis surveillance in France, 2000-2003. Euro Surveill 2004;9:7-8.

2. Ndeikoundam $\mathrm{N}$, Viriot $\mathrm{D}$, Fournet $\mathrm{N}$, et al. Les infections sexuellement transmissibles bactériennes en France: situation en 2015 et évolutions récentes. Bull Epidemiol Hebd 2016:738-44.

3. European Centre for Disease Prevention and Control. Annual Epidemiological Report 2016 - Syphilis. Stockholm: European Centre for Disease Prevention and Control, 2015.

4. Pialoux G, Delaugerre C, Cotte L, et al. Pre-exposure prophylaxis: a useful tool to prevent human immunodeficiency virus infection? Clin Microbiol Infect 2016;22:757-67.

5. Newman L, Rowley J, Vander Hoorn S, et al. Global Estimates of the Prevalence and Incidence of Four Curable Sexually Transmitted Infections in 2012 Based on Systematic Review and Global Reporting. PLoS One 2015;10:e0143304.

6. La Ruche G, Goulet V, Bouyssou A, et al. [Current epidemiology of bacterial STIs in France]. Presse Med 2013;42(4 Pt 1):432-9.

7. Moulis G, Lapeyre-Mestre M, Palmaro A, et al. French health insurance databases: what interest for medical research? Rev Med Interne 2015;36:411-7.

8. Tuppin P, de Roquefeuil L, Weill A, et al. French national health insurance information system and the permanent beneficiaries sample. Rev Epidemiol Sante Publique 2010;58:286-90.

9. Fonteneau L, Ragot M, Guthmann JP, et al. Use of health care reimbursement data to estimate vaccination coverage in France: Example of hepatitis $B$, meningitis $C$, and human papillomavirus vaccination. Rev Epidemiol Sante Publique 2015;63:293-8.
10. Janier M, Unemo M, Dupin N, et al. 2014 European guideline on the management of syphilis: giving evidence priority. J Eur Acad Dermatol Venereol 2016;30:e78-e79.

11. Janier M, Dupin N, Bouscarat F, et al. [Late syphilis]. Ann Dermatol Venereol 2016;143:725-8.

12. Janier M, Dupin N, Spenatto N, et al. [Primary syphilis]. Ann Dermatol Venereol 2016;143:720-4.

13. Ghanem KG. Management of Adult Syphilis: Key Questions to Inform the 2015 Centers for Disease Control and Prevention Sexually Transmitted Diseases Treatment Guidelines. Clin Infect Dis 2015;61(Suppl 8):S818-36.

14. Bibbins-Domingo K, Grossman DC, Curry SJ, et al. Screening for Syphilis Infection in Nonpregnant Adults and Adolescents: US Preventive Services Task Force Recommendation Statement. JAMA 2016;315:2321-7.

15. Richaud-Eyraud E, Brouard C, Antona D, et al. Dépistage des maladies infectieuses en cours de grossesse: résultats de l'enquête Elfe en maternités, France métropolitaine, 2011. Bull Epidémiol Hebd 2015:254-63.

16. Marty L, Cazein F, Panjo H, et al. Revealing geographical and population heterogeneity in HIV incidence, undiagnosed HIV prevalence and time to diagnosis to improve prevention and care: estimates for France. J Int AIDS Soc 2018;21:e25100.

17. La Ruche G, Le Strat Y, Fromage M, et al. Incidence of gonococcal and chlamydial infections and coverage of two laboratory surveillance networks, France, 2012. Eurosurveillance 2015;20:21205-15.

18. Fonteneau L, Ragot M, Parent du Châtelet I, et al. The use of reimbursement data for timely monitoring of vaccination coverage: the example of human papillomavirus vaccine following public concerns about vaccine safety. BMC Public Health 2015;15:1233.

19. Owusu-Edusei K, Chesson HW, Gift TL. The economic burden of pediculosis pubis and scabies infections treated on an outpatient basis in the United States: evidence from private insurance claims data, 2001-2005. Sex Transm Dis 2009;36:297-9.

20. Owusu-Edusei K, Carroll DS, Gift TL. Examining fluoroquinolone claims among gonorrhea-associated prescription drug claims, 20002010. Am J Prev Med 2015;49:761-4.

21. Owusu-Edusei K, Roby T, Wright SS, et al. The consistency of relative incidence rates of nonviral sexually transmissible infections from health insurance claims and surveillance data, 2005-10. Sex Health 2013;10:400-7.

22. Wetten $\mathrm{S}$, Mohammed $\mathrm{H}$, Yung $\mathrm{M}$, et al. Diagnosis and treatment of chlamydia and gonorrhoea in general practice in England 2000-2011: a population-based study using data from the UK Clinical Practice Research Datalink. BMJ Open 2015;5:e007776.

23. Centers for Disease Control and Prevention. Sexually Transmitted Disease Surveillance 2015. Atlanta: U.S.: Department of Health and Human Services, 2016.

24. Filipovic-Pierucci A, Rigault A, Fagot-Campagna A, et al. L'état de santé des populations des départements d'outre-mer en 2012, comparativement à la métropole : une analyse de la base nationale de l'Assurance maladie. Revue d'Épidémiologie et de Santé Publique 2016;64:175-83.

25. Bocquier $A$, El-haïk $Y$, Jardin $M$, et al. Intérêt des données de remboursement de l'assurance-maladie pour l'étude des disparités territoriales de la prévalence de l'asthme : une étude en ProvenceAlpes-Côte d'Azur. Revue d'Épidémiologie et de Santé Publique 2015;63:155-62.

26. La Ruche G, Le Strat $Y$, Fromage M, et al. Incidence of gonococcal and chlamydial infections and coverage of two laboratory surveillance networks, France, 2012. Euro Surveill 2015;20:21205-15. 